\title{
A infância e o direito de brincar: da didatização do lúdico à expressão livre das crianças
}

Resumo: Este artigo integra os estudos teóricos realizados pelo grupo de pesquisadores participantes do projeto "Estudo do perfil das brinquedotecas em Centros Municipais de Educação Infantil brasileiros". Trata-se de pesquisa bibliográfica e documental a partir das orientações legais sobre a infância e o direito de brincar (BRASIL, 1990, BRASIL, 2005, BRASIL, 2005) e literatura da educação infantil (SANTOS, 2000; POSTMAN, 2002; DAHLBERG; MOSS; PENCE, 2003; FRIEDMAN, 2005; KRAMER, 2007), dentre outros. O estudo direcionou-se à infância e ao direito de brincar e a análise possibilitou compreender que, ao mesmo tempo em que a concepção de infância modificou-se nos documentos legais reconhecendo-a enquanto sujeito histórico, social e cidadã, o direito de brincar também assumiu novos sentidos, como o de essencialidade das expressões infantis. No entanto, cabe considerar que nem sempre tal expressão encontra livre espaço na escola, decorrendo em desafios e busca por processos formativos que possibilitem a compreensão sobre o lugar do brincar na escola, não apenas enquanto atividade pedagógica, mas como linguagem e expressão livre da criança que aprende e se desenvolve.

Palavras-chave: Educação Infantil. Legislação. Direito de Brincar.

\section{Childhood and the right to play: from the didatization of the playful to the free expression of children}

Abstract: This article is part of the theoretical studies carried out by the group of researchers participating in the project "Study of the profile of toy library in Brazilian Municipal Schools of Early Childhood Education". It is a bibliographical and documentary research, based on the legal guidelines on childhood (BRAZIL, 1990, BRAZIL, 2005, BRAZIL, 2005) and literature on children's education (SANTOS, 2000, POSTMAN, 2002; DAHLBERG; MOSS; PENCE, 2003; FRIEDMAN, 2005; KRAMER, 2007), among others. The study observed the childhood and the right to play. The analysis made it possible to understand that at the same time that the conception of childhood was modified in the legal documents recognizing it as a historical, social and citizen subject, the right to play also assumed new meanings such as that of essentiality in children's expressions. However, it is possible to consider that this expression. does not always find free space in the school, resulting in challenges and search for formative processes that allow the understanding of the place of play in the school, not only as a pedagogical activity, but as a free expression and language of the child Learns and develops.

Keywords: Child Education. Legislation. Right to Play.

\footnotetext{
Mestre em Educação pela Universidade Estadual de Londrina. Docente do Curso de Pedagogia - modalidade de ensino à distância - UNOPAR. E-mail: raquel.ferronato@kroton.com.br

2 Doutora em Psicologia pelo Programa de Pós-Graduação em Psicologia pela Universidade Estadual Paulista Júlio de Mesquita Filho. Docente Titular do Programa de Pós-Graduação Stricto Sensu da UNOPAR-Metodologias para o Ensino de Linguagens e suas Tecnologias. E-mail: luannbi@gmail.com

${ }^{3}$ Mestre em Educação pela Universidade Estadual de Londrina Docente do Curso de Pedagogia - modalidade de ensino à distância - UNOPAR. E-mail: pproscencio@gmail.com
} 


\section{Introdução}

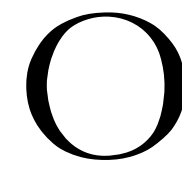

conceito de infância foi criado há pouco mais de 200 anos e, embora seja construído e reconstruído continuamente, o modo como é concebido nos dias atuais pode conservar traços de concepções que pertenceram a outros tempos e contextos, como é o caso da visão idealista da infância enquanto idade de inocência, como um dado atemporal e universal ou, ainda, como período de grandes potencialidades humanas com progressão linear, cumulativas e previsíveis. A questão é que, ao analisar a história da infância, são observados avanços e retrocessos em relação à sua concepção, decorrente da convivência dos adultos com as crianças, dos valores, costumes e ideais de grupos sociais, dos quais participaram.

Sendo a infância uma categoria social pertencente a determinada cultura e momento histórico, originam-se diferentes modos de vivê-la e, consequentemente, uma multiplicidade de modos de contemplar os direitos da criança. No caso da família, a forma de conceber os filhos como propriedade dos pais aos quais são atribuídos poderes e mecanismos que lhes permitam dar conta da sua tarefa, por exemplo, também sofreu significativas alterações, implicando uma nova forma de se relacionar com as crianças e de reconhecer suas diferentes expressões como o brincar.

A partir dessas ideias, o presente estudo discute sobre a criança enquanto cidadã, seus direitos legais, dentre eles, o de brincar.

\section{A criança cidadã}

A infância brasileira sentiu a reorganização institucional e legal iniciada a partir da redemocratização do país, incluindo, nas suas perspectivas, mudanças decisivas em prol dos direitos da criança. No entanto, ao abordar a temática dos direitos da criança, a perspectiva que deve ser considerada é aquela que parte do plano ideal para o vivido no cotidiano das crianças.

Nas últimas décadas do século XX, foram muitas as conquistas legais no campo dos direitos da criança dentro do ordenamento jurídico brasileiro, como a lei sobre o Sistema Único de Saúde (Lei 8.080/90) e a Lei Orgânica da Assistência Social (Lei 8.742/93). Ao considerar o tema dos direitos da criança, é preciso lembrar que se fala em direitos consubstanciados na Carta Magna de 1988, no Estatuto da Criança e do Adolescente (ECA) e na Lei de Diretrizes e Bases da Educação Nacional (LDB), e os justificam com argumentos convincentes. Em contrapartida, tendo em vista o cenário atual internacional e nacional, é extremamente desafiador garantir-lhes uma proteção efetiva, capaz de transformar esses direitos em exigências concretas e reais vivências no universo da criança.

Em meio aos avanços legais e sociais, concernentes ao status da criança, o paradoxo mostra-se claro diante do que é enunciado na lei e a sua consecução, entre teoria e prática e, ainda, entre as 
promessas e as poucas realizações. Nas palavras de Martins (1999), as leis voltadas para a infância são um conjunto de aspirações partilhadas por cumprir, ou seja, há uma defasagem entre dois tempos distintos que coexistem: o tempo legislativo e o tempo social.

A Convenção dos direitos da Crianças (CDC) foi ratificada pelo Estado brasileiro e, em seguida, a constitucionalização estabeleceu os direitos como fundamentais. Faria (2000, p. 212) afirma que os direitos fundamentais, como o direito à educação e o direito ao lazer, “[...] são princípios que orientam a forma pela qual o Estado deve se organizar e atuar, traçando finalidades capazes de guiar a atividade estatal e a vida em sociedade, priorizando o bem-estar individual e coletivo dos seus integrantes".

Compreende-se que os direitos da criança, reconhecidos na ordem internacional como desejáveis, são apenas princípios que precisam ser efetivados na ordem interna de cada Estado, ou seja, eles serão aplicáveis e executáveis a partir de um determinado ordenamento jurídico.

Destaca-se que, entre o século XIX e começo do século XX, foram observados novos padrões sociais, culturais e econômicos no Brasil impostos pela modernidade, pela industrialização, pela urbanização e pela crescente marginalização social das camadas populares (SANTOS, 2000). A sociedade brasileira, até então marcadamente rural, convivia, agora, com uma realidade também caracterizada pela urbanidade em função do processo de industrialização. As cidades cresciam econômica, geográfica e urbanisticamente. Com esse crescimento sem planejamento, aconteceu o fenômeno do inchaço da cidade com prejuízos sociais à população, já que a saúde, a alimentação, a habitação e as condições de trabalho eram precárias, dessa forma, “[...] nesse contexto, verifica-se o surgimento ou o agravamento de crises sociais que outrora eram pouco relevantes no cotidiano da cidade" (SANTOS, 2000, p. 213).

Uma das consequências diretas da crise social gerada pela industrialização foi o aumento da ocorrência de crimes, reflexos de uma maior incidência de conflitos urbanos. É nesse cotidiano de transformações que se insere a criança e o adolescente brasileiro do início do século XX, em que, por um lado, há crescimento econômico, industrial e urbano e, por outro, o agravamento das crises sociais, proliferação dos cortiços, marginalidade, miséria e criminalidade.

Santos (2000, p. 214) aponta que a criança e o adolescente marginalizados socialmente encontraram, nas ruas da cidade, "o local perfeito para colocar em prática as artimanhas que garantiriam sua sobrevivência". Assim, era significativo o número de menores que praticavam crimes devido à "deterioração das condições sociais, as modificações das formas e modos de relacionamento", além disso, "os diferentes e novos padrões de convívio que a urbanidade impunha a seus habitantes eram ignorados pelo discurso oficial, que estabelecia a oposição entre lazer-trabalho e crime-honestidade" (SANTOS, 2000, p. 215).

O Estado não tinha um programa de ação para enfrentar as consequências sociais advindas da urbanização e recorria, não raras vezes, ao discurso moralista de cunho elitista (somam-se o caráter interventivo e repressor), que não tinha a preocupação de investigar e afirmar políticas públicas sérias e efetivas. Esse discurso não buscava conhecer as raízes do problema e estigmatizava a criança e o adolescente (o menor), partindo do pressuposto de que todos aqueles que não se inserissem no processo produtivo - incluindo aí as crianças - estavam condenadas à vadiagem. O crime de "vadiagem" à época 
era previsto no art. 399 e 400 do Código Penal de 1890, logo, vadios eram considerados também aqueles que, rejeitados pelo mercado formal, sobreviviam no mercado informal.

O Código de Menores de 27 foi conhecido como Código Mello Matos e legou, às crianças e adolescentes brasileiros, o estigma de ser "menor". Pesavam sobre eles o estigma da marginalização por pertencer às classes pobres que viviam em situação de miséria. Foi a primeira legislação específica voltada para essas categorias e partia do pressuposto de que o contexto social desse "menor" era marcado pela criminalidade. Em certo ponto, aqui está o cerne do termo "menor", ou seja, um determinado grupo de crianças e adolescentes, representando um setor específico, identificado com a delinquência, a marginalidade e o abandono. A criança e o adolescente marginalizados social e economicamente tornaram-se objeto de intervenção da Justiça de Menores, ou seja, destinava-se somente aos "desajustados sociais". Claro está que as condições sociais, econômicas e culturais dessas classes sofriam um processo de patologização social.

O Código de Menores de 1979 definiu a conhecida doutrina da situação irregular do menor. Não se conferia às crianças à possibilidade de reivindicar a exigibilidade de um direito, pois esses não eram enunciados expressamente no comando normativo. Seu ponto marcante foi a atribuição e responsabilização da família pela educação dos seus filhos. Porém, as condições peculiares de muitas famílias brasileiras eram limitadas por condições sociais e econômicas, ou seja, apregoa-se que a criança e o adolescente têm direito ao bem-estar e ambiente harmônico, mas esta afirmação não é entendida como direito, o que significa que se a norma não elenca claramente o direito a sua exigibilidade e efetivação fica totalmente comprometida.

A doutrina da situação irregular, associada à ideia de estigma social, não alcançava todas as crianças e adolescentes, mas somente possuía eficácia jurídica quando determinada conduta de um menor se adequava às situações que caracterizavam a situação irregular.

Num contexto onde regulação, cuidado e proteção se mesclam, a (pre)ocupação de entidades públicas e privadas com as crianças e adolescentes pobres é, também, uma (pre)ocupação pela manutenção da ordem pública. Daí que sob o pretexto da proteção de vulneráveis foi promulgada a primeira lei específica voltada para crianças e jovens, datada de 1927 que passou a controlar e regular as formas de "assistência" ao chamado "menor". O denominado Código de Menores (BRASIL, 1979), a partir da doutrina da situação irregular, visava impor mecanismos de disciplina, fazendo circular os efeitos do poder a partir de uma infância concebida como "problema social" porque em "situação irregular" (ZUCHETTI; MOURA, 2017, p. 65).

A Constituição Federal de 1988 consubstancia os preceitos internacionais em relação à infância, albergando, em seu texto, o reconhecimento dos direitos da criança e da necessária proteção integral que deve prestar à família, à sociedade e ao poder público de forma complementar tal como o previsto no disposto artigo 227 da Carta Magna. A criança merece tratamento de respeito e esta é uma das razões que levaram a Carta Magna de 1988 a cultuar o princípio de dignidade inerente à sua pessoa, acolhendo-a no ordenamento jurídico e afirmando sua participação do mundo dos direitos e deveres e que nada mais é do que o mundo da cidadania.

No plano prático, a força obrigacional dos direitos da criança e do adolescente encontra desafios para traduzir-se em medidas efetivas e plenas de proteção à criança. No entanto, é preciso reconhecer que a nova doutrina relativa aos cuidados com a criança e a nova maneira de enxergar o sujeito detentor de 
direitos são prerrogativas de um instrumento ativo de consolidação de tais direitos. A partir da Constituição Federal de 1988 e a pressão dos movimentos sociais, houve a aprovação de um conjunto de leis, tais como O Estatuto da Criança e do Adolescente em 1990, a Lei Orgânica da Assistência Social (BRASIL, 1993) e Lei de Diretrizes e Bases da Educação Nacional (BRASIL, 1996).

A luta pelos direitos revela que "o tema da infância tem estado presente no Brasil há pelo menos duas décadas, não só nas discussões teóricas que orientam a pesquisa acadêmica, mas também nas políticas públicas e nas lutas dos movimentos sociais" (BAZÍLIO; KRAMER, 2003, p. 13). Ainda, Candau (2003, p. 10) afirma que “[...] a maior parte dos cidadãos latino-americanos tem pouca consciência de que são sujeitos de direito. Esta consciência é muito débil, especialmente em contextos como o nosso, marcados por uma cultura clientelista e autoritária em que os direitos são vistos como 'dádivas' ”.

\section{A criança como sujeito de direitos e liberdades}

Há uma aprovação generalizada dos direitos das crianças, o que seria difícil de imaginar em outros séculos atrás e, por essa razão, o seu reconhecimento constitui uma revolução. No entanto, essa inquestionável valorização nos contextos nacionais não deve levar à enganosa conclusão de que hoje realmente eles sejam observados e respeitados pelo mundo todo.

Os direitos da criança são frutos de uma longa luta em favor da construção de uma sociedade democrática cujos princípios baseiam-se nos princípios de igualdade, liberdade e fraternidade. A criança, como realidade ontológica, sempre existiu e constitui-se dentro de uma trajetória de concepções acerca da sua afirmação. Hoje, essa fase do desenvolvimento humano passa a ser reconhecida e alcança o estatuto jurídico de sujeito de direitos que pertence ao mundo, ou melhor, ao mundo dos cidadãos. A infância, como um lugar de direitos e de exercício de cidadania, constitui-se um dos elementos-chave da concepção contemporânea de criança. Dessa maneira, ser sujeito de direitos é ser titular de uma identidade social que permite, às crianças e aos adolescentes, a busca de uma proteção especial (art. $6^{\circ}$ do ECA).

Todavia, é necessário não descuidar da ideia de que a criança pertence a um contexto social que existe antes de ela nascer e, que mediante a sua internalização e ação sobre esse contexto, ela entra em contato com uma realidade na qual a violência, a opressão de classes, a comercialização e a exploração são elementos constantes. Assim, os direitos das crianças devem ser contextualizados nessa realidade em que elas existem e fazem parte, caso contrário, será apenas uma ilusão à sociedade e às crianças, e isso é não levá-las a sério ou respeitá-las (DAHLBERG; MOSS; PENCE, 2003).

A jornada pelo reconhecimento dos direitos fundamentais é uma contínua caminhada em direção à consolidação dos Estados Democráticos. No contexto das lutas pela consolidação dos Estados Democráticos, a criança, na sua condição de sujeito de direitos, passa a integrar os textos legais, em que sua projeção reconhece a especificidade do universo infantil em relação aos direitos do mundo adulto. No entanto, é preciso destacar que não é somente pela característica de o ser humano criança e adolescente diferenciar-se do adulto que justifica um sistema jurídico de proteção especial. Não é meramente a sua 
diversidade de condição em relação ao adulto que legitima um tratamento abrangente e efetivo aos direitos, mas aliado a essa condição diversa, soma-se a sua vulnerabilidade em relação ao adulto.

A libertação e a afirmação da infância ganharam nos textos normativos internacionais e nacionais a sua maior bandeira de luta em prol de um período peculiar do desenvolvimento da infância. Como bem observou Larrosa (2004), a afirmação desse "outro" garante à infância o reconhecimento de suas especificidades e de suas necessidades em relação ao mundo adulto.

A finalidade dos direitos da criança em buscar da igualdade de condições em relação ao mundo adulto apresenta uma contraposição que merece ser destacada. Essa situação aparece quando as especificidades e necessidades próprias da infância, ou seja, a sua alteridade, confronta-se com a sua observável dependência e imaturidade em relação ao mundo adulto. Sabe-se que as condições da infância não são iguais às condições e necessidades adultas, na medida em que as prerrogativas e possibilidades diferem-se essencialmente da condição adulta. Talvez, em relação a essa contraposição é que se afirma o ponto de vista da necessidade de buscar a definição concreta e específica dos direitos da criança, já que essas diferenças geram um certo mal-estar a respeito do seu reconhecimento.

A gradual conscientização que encara a criança como um "outro" alia-se ao processo gradativo de afirmação de seus direitos e fundamenta-se na busca de igualdade e a condição inegável de vulnerabilidade e fragilidade da criança. Dessa maneira, consolida-se a necessidade de reunir em um conjunto os direitos da criança, o que pode ser considerado uma evolução no sentido de que o reconhecimento da singularidade e especificidade da criança já não bastava para garantir suas necessidades e exercício da cidadania. Esse corpo de direitos the atribui uma condição peculiar em relação ao adulto.

O ECA traz em seu contexto uma mudança radical em relação aos seus princípios e concepções. As mudanças ocorreram em relação à doutrina, à legislação e à política que antes destinavam-se ao "menor em situação irregular". A chamada doutrina da situação irregular postulava a concepção de criança e de adolescente de forma indistinta, em que ambos eram considerados como "menores".

A confusão conceitual entre os termos "crianças" e "adolescentes" decorre das políticas públicas de atendimento voltadas para a infância desvalida e adolescentes autores de crimes, já que ambos os grupos recebiam o mesmo tratamento, sob a ótica da assistência concreta que lhes era prestada. E mesmo o ordenamento jurídico os tratava de forma idêntica e "esta confusão conceitual [...] acabou por gerar fundas violações aos direitos fundamentais mais básicos de ambos os grupos" (MACHADO, 2003, p. 29, grifo do autor). O Estatuto da Criança e do Adolescente (Lei complementar no 8.069/1990) é "um instrumento jurídico que transpõe para o plano nacional os direitos previstos na Convenção dos Direitos da Criança, prevê a adoção de mecanismos e fornece diretrizes para que as políticas públicas possam estar equipadas para promover os direitos da criança" (BRASIL, 2003, p. 3).

O ECA instaura um novo paradigma na ordem nacional em relação ao tratamento destinado à criança e ao adolescente no sentido de considerá-los como sujeito de direitos em condição peculiar de desenvolvimento, garantindo-lhes, por meio de responsabilidade e mecanismos, a condição de sujeitos de direitos fundamentais e individuais assegurados pelo Estado e pela sociedade com absoluta prioridade 
(BAZÍLIO; KRAMER, 2003). Este é o fundamento da doutrina da proteção integral, que nasce da contraposição do direito do menor, garantindo um direito mais amplo, o direito fundamental à infância.

A prioridade absoluta, prevista no art $4^{\circ}$ do ECA, torna-se um princípio norteador das obrigações legais em relação à infância e significa que deve ser garantido por meio da formulação de políticas públicas capazes de preservar os direitos da criança. Dessa maneira, os critérios de elegibilidade para qualquer política pública voltada para a infância (tanto de atendimento como de defesa de direitos) devem contemplar a realidade da situação brasileira.

A concepção doutrinária do paradigma da proteção integral considera como princípio basilar a noção de que a criança e o adolescente estão em uma situação peculiar do desenvolvimento humano e que, nesta referida condição, são portadores de direitos essenciais especiais em relação ao adulto que já goza de todas as capacidades para exercer os seus direitos e deveres.

$\mathrm{O}$ artigo $3^{\circ}$ do ECA afirma três princípios fundamentais destinados à criança e ao adolescente. O primeiro testifica que as crianças e adolescentes gozam de todos os direitos fundamentais que estão assegurados a toda pessoa humana. O segundo destaca que eles têm direito à proteção integral que é a eles atribuída, garantindo-se todos os instrumentos necessários para assegurar seu desenvolvimento físico, mental, moral e espiritual, em condições de liberdade e dignidade.

O ECA avançou nos seguintes aspectos: (a) a concepção de "menor" foi substituída pelo conceito de "criança e adolescente" que segundo o art. 1 e o art. 6 do ECA, são consideradas como pessoas em condição peculiar de desenvolvimento. O reconhecimento de que as crianças e os adolescentes diferem-se entre si garante-lhes o reconhecimento de seus direitos já que cada qual possui características e necessidades distintas; (b) de acordo com o art.4, à criança e ao adolescente devem ser garantidos com absoluta prioridade todos os direitos conferidos pela lei; (c) a interpretação da criança e do adolescente com base nas suas carências (menor socialmente desfavorecido, abandonado ou delinquente) passa a ser o de pessoas em desenvolvimento, ou seja, sujeito de direitos judicialmente exigíveis; (d) segundo o art. 4 do ECA, os direitos da criança e do adolescente devem ser respeitados e garantidos pela família, pela comunidade, sociedade em geral e pelo Poder Público. Trata-se da responsabilidade compartilhada estabelecida no art. 227 da CF/88 e, que conjugado com o art. 4 do ECA, fundamenta a doutrina da proteção especial. Tais artigos rompem com a perspectiva repressora e correcional, segundo os quais a criança e o adolescente em situação de abandono e/ou de conflito com a lei constituíram uma questão a ser resolvida pela polícia e pela justiça.

A possibilidade de desenvolver a personalidade humana, ou seja, as potencialidades do ser humano adulto, constituem a essência da noção jurídica de personalidade. Segundo a doutrina tradicional, o termo "pessoa" vem a ser o ente físico ou coletivo suscetível de direitos e obrigações, aí também entendido como sinônimo de sujeito de direito. Entende-se por sujeito de direito aquele que é sujeito de uma pretensão ou titularidade jurídica, ou, em outras palavras, do poder de intervenção na produção da decisão judicial. É incerta a origem do vocábulo "pessoa". Etimologicamente, indica que a palavra pessoa vem do latim persona, que, em uma adaptação à linguagem teatral, significava máscara. Segundo Diniz (2001), o termo "pessoa" recebeu três 
acepções diferentes: 1) acepção vulgar em que o termo é sinônimo de ente humano, não se adaptando, portanto, à linguagem jurídica, pois as pessoas jurídicas não são pessoas humanas, mas têm uma conotação que lhes dá a conformação de pessoa; 2) acepção jurídica, sendo pessoa o ente físico ou moral que tem aptidão genérica para adquirir direitos e contrair obrigações. Existe um sujeito que tem a função de exercer a titularidade, podendo tanto ser o homem - caso da pessoa física, ou pessoa natural -, ou um agrupamento de homens ligados a um interesse comum - caso da pessoa jurídica, ou pessoa coletiva; e 3) acepção filosófica, que considera a pessoa como o indivíduo agindo de modo consciente na realização da finalidade moral, circunstância em que se considera o homem ou uma coletividade no sentido amplo de pessoa.

Soares (1997) afirma que qualquer sociedade que reconheça os direitos da criança a considera como pessoa com um estatuto socialmente reconhecido. No entanto, a autora observa que isso significa não tratá-la como um adulto, mas entender que são vulneráveis e "devido a tal precisam de consideração e serviços especiais diferentes dos adultos" (SOARES, 1997, p.15). Outra perspectiva apontada pela referida autora é a paternalista, que defende a incapacidade da criança em tomar decisões razoáveis e informadas que serão adquiridas com a sua condição futura de maior maturidade e de capacidade de fazer escolhas mais racionais. Destaca-se, aqui, o fundamento da falta de experiência da criança como um dos obstáculos ao exercício dos seus direitos de participação.

Os direitos fundamentais destinados à criança e ao adolescente baseiam-se no interesse especial de sua proteção jurídica no sentido de que estes estão em condição peculiar de desenvolvimento, já que estão formando, desenvolvendo a sua personalidade. No entanto, é preciso frisar que, segundo a doutrina jurídica, há uma longa discussão sobre os aspectos diferenciais entre a personalidade adulta e a personalidade infanto-juvenil. O próprio texto constitucional elenca uma conformação estrutural distinta dos direitos da criança e do adolescente.

É dever de todos os adultos assegurar os direitos da criança e do adolescente, ou seja, trata-se de uma prestação positiva em relação a todos os direitos destinados a eles. A conformação igual dos direitos fundamentais contidos no rol do art. 227 obriga de uma forma eminente a prestação positiva, pois além do emprego da expressão "é dever assegurar", o sentido da parte final do dispositivo parece inequívoco, "é comandar que os adultos ativem-se, ajam comissivamente, para evitar violação dos direitos fundamentais de crianças e adolescentes, ou recompố-los quando já violados" (MACHADO, 2003, p. 386, grifos do autor). Isso advém do disposto no art. $2^{\circ}$ da CDC (1989) que impõe a obrigação genérica para os Estados de agir de forma a assegurar a concretização das suas disposições que não são apenas de natureza programática, mas também obrigações concretas de agir.

Os princípios gerais voltados para os direitos da criança foram estabelecidos na Constituição Federal de 1988 que "dentre os seus princípios fundamentais, consagra o objetivo de promover o bem de todos, sem preconceitos de origem, raça, sexo, cor, idade e quaisquer formas de discriminação" (BRASIL, 2003, p. 24). O princípio do interesse superior da criança está estabelecido no art. 227 da CF/88, o qual determina que à família, ao Estado e à sociedade cabem a "responsabilidade compartilhada" na educação e cuidados da criança e do adolescente com absoluta prioridade, já que estes são reconhecidos como 
pessoas em condição peculiar de desenvolvimento, com necessidades peculiares e que requerem proteção integral. A responsabilidade da família, da sociedade e do Estado são três instâncias reais e formais de garantia dos direitos elencados na lei. A família na sua condição primeira, natural e básica é a primeira instância. Ao Estado, cabe garantir as condições mínimas para que a família possa exercer suas funções.

Os direitos expostos no referido artigo podem ser classificados como direitos relativos à sobrevivência (vida, saúde, alimentação), direitos relativos ao desenvolvimento pessoal e social (educação, cultura, lazer e profissionalização) e direitos relativos à integridade física, psicológica e moral (dignidade, respeito, liberdade, convivência familiar e comunitária).

A interpretação das leis voltadas para a infância e adolescência deverão ser consideradas de acordo com a sua finalidade social, as exigências do bem comum, os direitos e deveres individuais e coletivos e a condição peculiar da criança e do adolescente como pessoas em desenvolvimento (art. $6^{\circ}$, ECA). A condição deles como pessoas em condição peculiar de desenvolvimento confere que não serão apenas garantidos estes direitos com absoluta prioridade (princípio do interesse superior da criança), mas terão direito à proteção especial devido à sua vulnerabilidade.

\section{O direito de brincar}

Há íntima relação entre a autonomia e a dignidade da criança. A autonomia constitui uma das palavras-chave para o entendimento da dignidade da condição da criança. Em outras palavras, é possível dizer que essas duas ideias são interligadas e fazem parte da determinação da própria condição da criança como sujeito de direitos. Considerando-se como premissa o entendimento que a dignidade humana é intocável e inabalável, toda busca pela reivindicação, consolidação e efetivação dos direitos da criança e sua autonomia assumirá funções prioritárias.

A ampliação de normas jurídicas com o intuito de regular as relações entre pais e filhos é, atualmente, uma das formas de ingerência do poder do Estado na educação das crianças, pois assume um caráter público relevante para a formação do cidadão. A Constituição Federal de 1988, em seu artigo 227, elenca os direitos fundamentais da criança: o direito à dignidade, à educação, à saúde, ao lazer, à alimentação, à profissionalização, à cultura, ao respeito, à vida, à liberdade e à convivência familiar e comunitária. Estes são deveres a ser respeitados e efetivados conjuntamente pela família, pela sociedade e pelo Estado de forma compartilhada.

A extensão de direitos fundamentais atribuídos à criança (art. 227, CF/88) é um avanço que, a passos lentos, vem se concretizando, mas que pode gerar um clima de incredulidade quando os olhamos pela lente da realidade da infância brasileira. De fato, embora eles sejam amplamente reconhecidos, não significa que foi conquistada a plenitude de sua efetivação por parte das instituições sociais que têm o dever de aplicálos nas situações cotidianas da vida infantil. Além do dever de atuação de todos os responsáveis em aplicar esses direitos, é dever assegurar e apoiar o seu exercício pela própria criança-cidadã, uma vez que reconhecer a criança como sujeito de direitos e de liberdades não é suficiente para garantir o exercício da cidadania e a proteção contra todas as formas de violência a que, muitas vezes, estão submetidas. 
A escola, como segmento da sociedade, tem o dever de garantir os direitos da criança modelando o seu contexto na busca de efetivá-los por meio de ações concretas, de mudança de postura e de transformação. Enfim, ela é um espaço a favor da condição da criança-cidadã e o educador deve ser considerado como um agente competente e promotor desses direitos. Reconhecer a criança como sujeito de direitos e dizer que ela é cidadã "é entender que tem direito à brincadeira, a não tomar conta de outras crianças, a não trabalhar, a não exercer funções que, em outras classes sociais, são exercidas por adultos” (KRAMER, 2003, p. 122-123).

Consoante a essa premissa, o brincar é considerado um direito de liberdade, portanto, fundamental para garantir o direito à infância e ao pleno desenvolvimento da criança que está em condição peculiar de formação. Por isso, destacamos que o brincar como direito de liberdade a ser exercido pela pessoa da criança nas suas manifestações singulares deve contar com o dever de apoio do educador também no contexto escolar.

A fundamentação jurídica do direito de brincar não é apenas uma questão relevante apenas no âmbito acadêmico, mas possui considerável relevância prática para sua normatização e implementação concreta no contexto escolar, cuja responsabilidade é garantir o melhor interesse da criança-cidadã.

É preciso considerar que esta fundamentação pode ter por base o direito individualista da relação entre pais e filhos no ambiente doméstico, bem como uma fundamentação dentro da perspectiva do direito público. A contraposição entre o direito público e o direito individualista, em uma atitude radicalista, pode levar ao apagamento dos direitos de liberdade da criança no ambiente coletivo ou o apagamento da responsabilidade da coletividade e a desconsideração dos contextos únicos que fazem parte do momento de vida da criança.

O direito de brincar encontra seu fundamento dentro do ordenamento jurídico internacional de forma clara. Na Declaração Universal dos Direitos da Criança - DUDC (ONU,1959), no seu princípio 4, ela inova o termo "proteção", que concede à criança o seu direito de brincar. Isso é um avanço significativo, pois na Declaração de Genebra (1924) não era reconhecido este direito, pois apenas elencava os direitos de proteção. A partir da DUDC (ONU, 1959), o brincar é uma vertente essencial dos chamados direitos de liberdade. Em consonância como o princípio 7 da DUDC (ONU, 1959), segundo parágrafo, contempla-se o parâmetro de interpretação de todos os direitos da criança que é o princípio do melhor interesse. Este princípio norteia todas as ações dos adultos e responsáveis pela sua educação e orientação. Da interpretação do seu terceiro parágrafo subentende-se o papel relevante atribuído aos jogos e às atividades livres da criança. O direito de brincar está expressamente destacado no art. 31 da Convenção dos Direitos da Criança - CDC (ONU, 1989, grifo nosso):

Art. 31. Os Estados Partes reconhecem o direito da criança ao descanso e ao lazer, ao divertimento e às atividades recreativas próprias da idade, bem como à livre participação na vida cultural e artística. Os Estados Partes promoverão oportunidades adequadas para que a criança, em condições de igualdade, participe plenamente da vida cultural, artística, recreativa e de lazer.

O que resulta disso é o entendimento do reconhecimento da infância que abarca o processo de descoberta de si e dos outros concedendo ao brincar e aos jogos uma condição indispensável para que ela usufrua de sua liberdade, em termos de agilidade, de faz-de-conta e de imaginação. Pelo fato de se 
reconhecer a criança como sujeito de direitos e de liberdades, destina-se a ela o reconhecimento de todas as suas manifestações primordiais como o próprio brincar e, por outro lado, sinaliza a conjugação entre os seus direitos e a responsabilidade educativa dos adultos para garantir a liberdade neste período de desenvolvimento humano.

O brincar é juridicamente um direito de liberdade da criança que é reconhecida como pessoa com interesses, desejos e vontades muito singulares. Por isso, deve ser garantido já que é sua realidade bem como um elemento indispensável para que ela se desenvolva de forma plena e saudável. O brincar é a manifestação da liberdade da criança e é reconhecido como um direito porque somente ela pode exercê-lo por si contando com o apoio, o respeito e o estímulo do adulto.

Dessa maneira, garantir e efetivar o direito de brincar é promover o bem-estar da criança e a valorização de sua individualidade como pessoa e cidadã desde o seu nascimento. $\mathrm{O}$ art. 16 do ECA fundamenta os direitos de liberdades da criança. O brincar é um dos conteúdos que compõem esse direito que tem um sentido objetivo, ou seja, é uma liberdade de fazer e de atuar em função das múltiplas atividades da criança.

É possível afirmar que o brincar é um dos elementos formadores da personalidade infantil, na medida em que ele pode ser tido como uma ação própria da infância, que deixou de ser tratada na legislação atual como um objeto passivo.

O direito de brincar na Constituição de 1988 se depreende da conjugação dos direitos ao lazer, à convivência familiar e comunitária, e ao direito ao não-trabalho, que é muito mais do que um "direito ao ócio". Por ser extensão do direito à infância, deve ser considerado como tutela autêntica, completa e compartilhada entre a família, a sociedade civil e o Estado, pois assim afirma a Constituição Federal de 1988.

Ao estabelecer, no art. 15 do ECA, que as crianças são titulares de liberdade, respeito e dignidade como pessoas em processo de desenvolvimento, quis o legislador que a eles fossem garantidos direitos básicos de caráter moral como prioridade absoluta constitucional. O ECA estabelece, neste artigo, os direitos de personalidade, oponíveis a todos, erga omnes, o que significa que quem se omite em situação concreta poderá ser responsabilizado.

O direito de brincar está estabelecido no ECA em seu Livro I da Parte Geral, sob a égide do Título II que trata dos direitos fundamentais, mais especificamente artigo 16 do Capítulo II que elencam os direitos de liberdade, ao respeito e à dignidade da criança: artigo 16 - O direito à liberdade compreende os seguintes aspectos: IV - brincar, praticar esportes e divertir-se.

O brincar como expressão do direito de liberdade da criança é um dos fundamentos do princípio da dignidade de sua pessoa. O reconhecimento do direito de brincar exposto no art.16, IV do ECA demonstra que a luta pelo reconhecimento da dignidade da infância venceu uma prova importante na aceitação dos ideais e da forma de vida infantil. O brincar consiste no direito de liberdade de ação da criança no sentido de que ela tem a possibilidade de escolha e de ação de acordo com suas motivações próprias.

$\mathrm{Na}$ verdade, qual é liberdade que a criança experimenta? Os dicionários apontam que liberdade é a capacidade de fazer o que quer. Contudo, as crianças e os adultos nem sempre sabem bem, ao certo, quais são 
as suas vontades e desejos, pois, muitas vezes, estes são até mesmo contraditórios. Como um exemplo, podese pensar naquelas coisas que são permitidas, mas inacessíveis, bem como outras acessíveis que são proibidas. Assim, essa liberdade é “[...] uma liberdade administrada, que deve ser obtida através da submissão a regras. O sujeito da educação aprende a ser livre, pelo acatamento de limites e das leis sociais” (BUJES, 2002, p. 12).

Embora a palavra "liberdade" tenha tantos significados, a tentativa aqui é buscar entendê-la de acordo com a singularidade das vivências infantis. Segundo o Dicionário de Filosofia (ABBAGNANO, 2007, p. 699), o vocábulo "liberdade" deriva do latim libertas e possui três significados fundamentais:

$1^{\circ}$ Liberdade como autodeterminação ou autocausalidade, segundo a qual a Liberdade é ausência de condições e de limites; $2^{\circ}$ Liberdade como necessidade, que se baseia no mesmo conceito da precedente, a autodeterminação, mas atribuindo-a à totalidade a que o homem pertence (Mundo, Substância, Estado); $3^{\circ}$ Liberdade como possibilidade ou escolha, segundo a qual a Liberdade é limitada e condicionada, isto é, finita.

A liberdade não é atribuída apenas a uma parte da criança, mas ao seu todo como pessoa, pois é uma possibilidade de escolha motivada por interesses específicos de sua idade. De acordo com o seu desenvolvimento, ela terá determinados interesses, desejos e manifestações que, em consequência, a motivarão em suas escolhas. Dessa maneira, o brincar é a liberdade de a criança produzir-se a si mesma. Brincando, a criança aprende a ser livre harmonizando o seu mundo interior nas suas mais variadas composições com o mundo exterior. O direito de brincar como um direito de liberdade é equilíbrio e felicidade.

A liberdade permite que a criança seja autora das escolhas que lhe interessam, fortalecendo a construção da sua autonomia de acordo com a sua lógica própria e “[...] levantando hipóteses na tentativa de compreender problemas que lhes são propostos pelas pessoas e pela realidade com a qual interagem" (WAJSKOP, 2005, p. 33). No entanto, o exercício da liberdade pode ser limitado pelo seu desenvolvimento, pelas condições sociais, ou ampliado pelo estímulo e apoio do adulto, especialmente, por meio do brincar.

É interessante apontar que o exercício do "auto-governo" e "das escolhas", a "gradativa independência" e a internalização das regras não se dão num espaço de infinitas possibilidades, mas dentro de limites estreitos que, no entanto, não são proclamados como tal. Não se trata de auto-regular-se, segundo escolhas livres: "não são todas as regras que podem ser modificadas em função de acordos feitos entre professores e crianças". A noção do desenvolvimento de uma moral autônoma é, na verdade, a imposição de uma pauta arbitrária de condutas tomadas como desejáveis, já preexistente no espaço social e cultural. (BUJES, 2000, p. 15).

Neste sentido, considera-se que a questão do exercício do direito de liberdade de brincar na infância é um dos temas importantes para a educação, porque a liberdade da criança restringe o poder do adulto que, de certa forma, não está preparado para conviver com o processo de construção da autonomia da criança. Isso significa que a criança só será livre quando lhe for permitido coordenar-se com a realidade e é justamente isso que lhe dá um poder de escolher entre possibilidades.

Por outro lado, o reconhecimento do papel social da criança tem levado muitos adultos a abdicarem de assumir seu papel. Parecem usar a concepção de "infância como sujeito" como desculpa para não estabelecerem regras, não expressarem seu ponto de vista, não se posicionarem. O lugar do adulto fica desocupado, como se para a criança ocupar um lugar, o adulto precisasse desocupar o seu, o que revela um distorção profunda do sentido da autoridade (KRAMER, 2007, p. 18, grifo do autor). 
O reconhecimento da autonomia e da capacidade de autorregulação da criança deve ser princípio básico para as atividades da escola e não o contrário. No entanto, reconhece-se que o espaço escolar é um espaço de contradições, mas é importante que ela procure ultrapassar as suas tensões no sentido de reconhecer que as crianças são sujeitos de direitos e que é um espaço institucional de educação. Por isso, os educadores devem ser capazes de compreender o que significa uma criança com autocontrole. Wajskop (2005, p. 30) afirma que a brincadeira aparece sempre como uma situação organizada:

[...] onde existe, para aquele que brinca, um certo número de decisões a tomar em uma ordem dada, mesmo que ela seja aleatória e indeterminada, como se pode constatar nos jogos das crianças pequenas. Esta característica da brincadeira é importante, no que se refere à influência que exerce no desenvolvimento infantil, especificamente no desenvolvimento do autocontrole da criança.

A liberdade que as crianças experimentam ao brincar permite-lhe expressar a sua sinceridade e a não-submissão às possíveis formas opressoras do mundo adulto. Os educadores devem também ser livres procurando dialogar e lembrar da história de sua infância, respeitando as marcas que essas the deixaram e que contribuem para a formação de outras múltiplas infâncias. A liberdade da criança relaciona-se intimamente com a liberdade que o educador experimentou na sua infância e, também, no exercício de sua profissão. No sentido jurídico, a liberdade consiste na faculdade ou poder outorgado à pessoa da criança para que possa agir segundo sua própria determinação respeitados, no entanto, as regras instituídas.

Daí a constatação lógica de que a liberdade da criança é uma liberdade muito sui generis. De fato, é muito contraditório dizer que um sujeito é titular do direito de liberdade mas não pode exercer esse direito. A liberdade é escolha. Se um sujeito não pode escolher, e outro sujeito está encarregado de escolher por ele, aquele sujeito não é livre. (VERCELONE, 2000, p. 19).

O termo "respeito" vem do latim respectus que é o "reconhecimento da dignidade própria ou alheia e comportamento inspirado nesse reconhecimento" (ABBAGNANO, 2007, p. 1008). O "respeito", no sentido jurídico, tem o mesmo valor que no sentido vulgar. A criança e o adolescente são merecedores de respeito em função de sua dignidade como pessoa humana. A dignidade vem do latim dignitas (ABBAGNANO, 2007) e é uma qualidade moral que, possuída pela criança, serve de base ao próprio respeito em que é tida. No sentido jurídico, entende-se a dignidade humana como a defesa de si próprio. No entanto, destaca-se que há dúvidas quanto a utilizar esse termo, porque o seu sentido pode ser entendido como uma "admiração romântica" ou referir-se a uma concepção "romantizada e essencialista de infância".

A criança reconhecida em si como pessoa tem um fim em si mesma, ou seja, como realidade ontológica ela possui as condições e competências para viver de forma plena a sua infância. Essa infância, única e irrepetível, não tem um valor relativo, pois ela é o fundamento absoluto da dignidade do ser infantil. Garantir o direito à infância por meio do direito de brincar é assegurar à criança a possibilidade de manifestar vivências insubstituíveis que propiciam o desenvolvimento integral de sua pessoa.

Considerar o brincar como um direito é reconhecer a dignidade da pessoa da criança, que tem o direito de liberdade para vivenciar essa possibilidade na sua infância. O princípio constitucional da dignidade da pessoa da criança fundamenta a ideia de que a infância não pode ser substituída por outras atividades que não lhes são próprias como, por exemplo, o trabalho infantil. 
A dignidade da criança constitui, portanto, um valor insubstituível dentro do ordenamento jurídico brasileiro que a reconhece como pessoa e não como coisa e isso pode ser traduzido no fundamento de que ela não é um meio para se atingir a adultez, mas um fim em si mesma. Machado (2003, p. 91) expõe que a dignidade humana "é um valor subordinante, que nunca cede em face dos valores subordinados". A dignidade da criança, conforme aponta a CF/88 nunca decai, porque é o fundamento do Estado Democrático de Direito.

É relevante que seja assegurado à criança a liberdade de brincar e dispor do tempo, no cotidiano escolar, para o pleno desenvolvimento de sua personalidade e de suas potencialidades. Libertar a criança é reconhecer o direito de, na medida do possível, dar-lhe a chance de governar a si própria e de ser ela própria. Em outras palavras, libertá-las é não abafar as suas almas e tirar a "oportunidade de serem elas mesmas" (FRIEDMAN, 2005, p. 13).

O ócio, considerado um mal para a sociedade capitalista, supõe que o jogo, mesmo o das crianças, seja definido pelo fato de não ser trabalho.De Masi (2000) escreve que a atividade criativa não se diferencia do jogo e do aprender. A ideia de que há separação entre estas duas dimensões é artificial, pois "quando trabalho, estudo e jogo coincidem, estamos diante daquela síntese exaltante que eu chamo de “ócio criativo" (DE MASI, 2000, p. 16). A oposição entre o brincar e o trabalhar entende que a brincadeira é "perder tempo", ou seja, não se vincula com o mundo produtivo que determina a produção de resultados considerações como úteis socialmente. Moyles (2006, p. 13-14) expõe que as discussões acerca do trabalhar/brincar e de polarizações semelhantes "são singularmente inúteis, pois, [...] a maioria de nós reconhece que é possível brincar no nosso trabalho e trabalhar no nosso brincar". A desvalorização do jogo na infância pode levar à desarmonia com a própria construção da identidade da criança desviando o processo de autodescoberta e sendo forçada a desenvolver uma personalidade e capacidades do jeito que os adultos acharem melhor.

$\mathrm{Na}$ sociedade dos adultos produtivos, as crianças e os idosos são relegados a um segundo plano, pois são considerados como improdutivos. Todavia, observa-se, por parte dos "adultos produtivos", uma preocupação com as crianças e suas vivências, mas não se descuidam de iniciá-las nos valores do sistema que são aceitos socialmente e que fazem parte do imaginário social. As intervenções dos adultos têm como finalidade integrar a criança a um mundo com códigos sociais de poder. Essa sociedade estruturada entende que a criança é vulnerável, é aquela que não fala e ainda "não é". Assim, o idoso também é discriminado porque é considerado aquele que já foi.

A oposição existente entre o jogo e o trabalho advém da sociedade que exige que as pessoas trabalhem, ou melhor, sejam produtivas. Kramer (2007) aponta que as crianças brincam para tentar descobrir e conhecer o mundo e essa atuação as liberta da obrigação de ser úteis. Cria-se uma contraposição entre produtividade e ócio bastante prejudicial para o reconhecimento da necessidade do homem em se divertir. De acordo com Sacristán (2005, p. 54), a questão da improdutividade da infância é uma das causas que justifica que "a retirada dos menores do mundo do trabalho foi uma referência importante (nesse caso uma ausência) para reconhecer a diferenciação do menor em relação ao adulto". 
Outro tópico interessante de observar é que o ECA traz, em seu texto, um contraponto necessário entre o direito de brincar em relação ao não-trabalho infantil. Wajskop (2005, p. 26) argumenta que o direito à infância é o direito ao não-trabalho "característico da brincadeira e que se constitui como o espaço que fornece a possibilidade da construção da identidade infantil autônoma, cooperativa e criativa". É interessante reconhecer que, para garantir o direito de brincar, é preciso garantir espaços destinados para que isso aconteça.

Por esta razão, é muito importante garantir os espaços públicos para que a criança possa brincar com segurança. Porém, é importante ressaltar que, mesmo que não haja espaços institucionais (por exemplo, brinquedotecas escolares) ou públicos (praças, parques, etc.) que permitam as manifestações lúdicas para as crianças, mesmo assim elas brincam reinventando e rompendo com a limitações do ambiente e do adulto que não permitem o brincar. A criança brinca independentemente de haver uma lei anterior que permita que ela o faça, independente de condições adversas ao seu desenvolvimento e bem como quando é submetida ao trabalho infantil nas suas mais variadas formas.

A cada dia, vê-se a escassez de tempo para o lúdico, em favor de afazeres diários e instrutivos, sendo o brincar visto como algo não sério e leviano: primeiro, faz-se o que é sério, depois é permitido brincar. Isso leva a crer que as condições físicas, históricas e sociais se modificam constantemente e acabam influenciando a atividade lúdica e o modo de brincar hoje, aspectos que atingem diferentemente cada classe social.

Postman (2002, p. 18) revela que a ideia de infância está desaparecendo devido aos estímulos que levam à adultização da criança, pois "tanto quanto as diferentes formas de vestir, as brincadeiras de criança, antes tão visíveis nas ruas das nossas cidades, também estão desaparecendo". O autor afirma que:

[...] os jogos infantis, em resumo, é uma espécie ameaçada. Como na verdade é a própria infância. Para onde quer que a gente olhe, é visível que o comportamento, a linguagem, as atitudes e os desejos - mesmo a aparência física - de adultos e crianças se tornam cada vez mais indistinguíveis. Certamente é por este motivo que existe um movimento crescente no sentido de reformular os direitos legais das crianças para que sejam mais ou menos os mesmos dos adultos. (POSTMAN, 2002, p. 18-19).

Isso não significa que as crianças de hoje têm menos capacidade para fantasiar ou para brincar do que outras gerações, mas, o que acontece hoje é que não se "concede espaço suficiente para que as fantasias pessoais se desenvolvam, e eles são continuamente violados pelos produtos de fantasias impessoais e desindividualizados da mídia” (BETTELHEIM, 1989, p. 177).

\section{Considerações finais}

As análises possibilitaram concluir que o direito de brincar (que se depreende dos arts. 16, 59, 70 e 71 do ECA) assume o contorno de essencialidade que o leva à condição de direito fundamental especial da criança enquanto ser humano e, embora assim considerado, há barreiras para efetivá-lo no contexto escolar. Apesar de constar no ordenamento jurídico como um direito, a caminhada para a compreender a essencialidade do brincar enquanto uma das linguagens infantis demanda a atenção dos movimentos sociais e dos profissionais da educação. Garantir na letra da lei é parte de um processo que exige a 
valorização da infância como etapa de formação humana. O contorno político, educacional e jurídico do direito de brincar, enquanto um ato de liberdade de escolha, é modelado pela concepção não de um devir, mas de reconhecer a criança cidadã como um sujeito de direitos e liberdades.

A maioria das pessoas parece concordar que toda criança tem o direito de brincar (pois até a Convenção sobre os Direitos da Criança no artigo 31 deixa isso claro), mas o que aparentemente está em discussão é se ela tem o direito de fazer isso em contextos educacionais. Embora haja diretrizes claras quanto à organização do trabalho com as crianças pequenas, é preciso refletir sobre a "didatização do lúdico" uma vez que na escola articula-se o brincar a aspectos pedagógicos. A escola formal não permite o prazer, nem mesmo o divertimento em seu contexto. As atividades pedagógicas dirigidas, pré-estabelecidas e com objetivos pedagógicos são preponderantes e deixam pouco espaço para brincadeiras livres criadas pelas crianças. A didatização do lúdico comporta práticas controladas pelo educador e as brincadeiras são "elemento de sedução oferecido à crianças". Nessas atividades, as crianças têm pouca margem para iniciativas próprias e o "controle pertencendo ao adulto garante apenas que o conteúdo didático seja transmitido".

Muitas vezes, utiliza-se o interesse da criança pela brincadeira para despistá-la em prol do objetivo escolar. Machado (1998, p. 33) considera ser preciso que os adultos não capturem a brincadeira em um lado amargo da vida, "[...] (ao pretender, por exemplo, que as crianças 'aprendam brincando' ou 'brinquem aprendendo'!). Este é o objetivo apenas de fabricantes de jogos educativos".

A brincadeira e o jogo têm função social e são produções elaboradas culturalmente, mas que só podem ser expandidas com a efetiva contribuição dos adultos, jovens e crianças em interação. As crianças, porém, desafiam essa didatização do lúdico quando inventam brincadeiras sem o consentimento do adulto, situações que acontecem nos intervalos das atividades formais, orientadas e supervisionadas sem o adulto perceber.

Assegurar o espaço para o exercício do direito de brincar dentro da educação infantil e do ensino fundamental importa na consolidação de um dever legal de constituição de um espaço digno e sadio que ofereça às crianças o seu pleno desenvolvimento e a ampliação de conhecimentos. A realização do direito de brincar passa pela consolidação de políticas públicas que garantam escola de qualidade como direito de todos. Que a escola seja um espaço para todos brincarem (adulto e criança) como forma de ser, estar e atuar em um mundo no qual as crianças existem e querem ter voz.

\section{Referências}

ABBAGNANO, Nicola. Dicionário de Filosofia. 5. ed. São Paulo: Martins Fontes, 2007.

BAZÍLIO, Luiz Cavalieri; KRAMER, Sonia. Infância, Educação e Direitos Humanos. São Paulo: Cortez, 2003.

BETTELHEIM, Bruno. Uma vida para seu filho: pais bons o bastante. 25 ed. Rio de Janeiro: Editora Campos, 1989. 
BRASIL. Relatório Consolidado ao Comitê sobre os Direitos da Criança. Brasília, DF, 2003.

BRASIL. Brasil Criança Urgente: a Lei 8069/90. 2. ed. São Paulo: Columbus, 1990. (Coleção Pedagogia Social, v. 3). $2005 \mathrm{a}$

Constituição Federal da República Brasileira de 1988. Curitiba: Imprensa Oficial do Paraná,

. Lei complementar. 8.069/90, de 13 de julho de 1990. Estatuto da Criança e do Adolescente. In: PESSOA, Fernanda. Legislação Educacional 3 em 1. São Paulo: RCN, 2005b.

BUJES, Maria Isabel Edelweiss. Que infância é essa? In: 23ª Reunião Anual da Associação Nacional de Pós-Graduação e Pesquisa em Educação (ANPEd), 2000, Caxambu (MG). CD-ROM da 23 ${ }^{\mathbf{a}}$ Reunião Anual da Associação Nacional de Pós-Graduação e Pesquisa em Educação (ANPEd). Rio de Janeiro (RJ): Associação Nacional de Pós-Graduação e Pesquisa em Educação (ANPEd), 2002. p. 1-15.

BUJES, Maria Isabel Edelweiss. Alguns apontamentos sobre as relações infância/poder numa perspectiva foucaultiana. In: REUNIÃO ANUAL DA ASSOCIAÇÃO NACIONAL DE PÓS-GRADUAÇÃO E PESQUISA EM EDUCAÇÃO, 26., 2003, Poços de Caldas, MG. Anais... Rio de Janeiro: ANPEd, 2003. p. 1-13. (CD-ROM).

Q Que infância é essa? In: REUNIÃO ANUAL DA ASSOCIAÇÃO NACIONAL DE PÓSGRADUAÇÃO E PESQUISA EM EDUCAÇÃO - ANPEd, 23., 2000, Caxambu, MG. Anais... Rio de Janeiro: ANPEd, 2000. p. 1-15. (CD-ROM).

CANDAU, Vera Maria F. (org.). Sociedade, educação e cultura(s). Petrópolis: Vozes, 2003.

DAHLBERG, Gunilla; MOSS, Peter; PENCE, Alan. Qualidade na Educação da Primeira Infância: perspectivas pós-modernas. Porto Alegre: Artmed, 2003. 263p.

DE MASI, Domenico de. O Ócio criativo. 8. ed. Rio de Janeiro: Sextante, 2000.

DINIZ, Maria Helena. Curso de direito civil brasileiro. 7 ed. v.1. São Paulo: Saraiva, 2001. 
FARIA, Camila Renault Pradez. Educação como Direito Fundamental: sua estrutura política e econômica em face das novas regras constitucionais e legais. In: PEREIRA, Tânia da Silva (org.). O Melhor Interesse da Criança: um debate interdisciplinar. Rio de Janeiro: Renovar, 2000. p.209-52.

FRIEDMAN, Adriana. O que é infância? Revista Pátio Educação Infantil. Porto Alegre: ARTMED, ano II, n.6, p.10-3, dez.2004/mar.2005.

KRAMER, Sônia. Infância e sociedade: o conceito de infância. In: KRAMER, Sônia. A Política do préescolar no Brasil: a arte do disfarce. São Paulo: Cortez, 2003, p.15-47.

A infância e sua singularidade. In: BEAUCHAMP, Jeanete; PAGEL, Denise; NASCIMENTO, Aricélia Ribeiro do (Orgs.). Ensino fundamental de nove anos: orientações para a inclusão da criança de seis anos de idade. Brasília: Ministério da Educação; Secretaria de Educação Básica, 2007. p. 13-24. Disponível em: < http://portal.mec.gov.br/seb/arquivos/pdf/Ensfund/ensifund9anobasefinal.pdf $>$. Acesso em: 21 set. 2016.

. Infância e sociedade: o conceito de infância. In: A Política do pré-escolar no Brasil: a arte do disfarce. São Paulo: Cortez, 1987. p. 15-47.

LARROSA, Jorge. Pedagogia Profana: danças, piruetas e mascaradas. 4. ed. Belo Horizonte: Autêntica, 2004.

MARTINS, Paula Cristina. Sobre a Convenção dos Direitos da Criança: da psicologia dos direitos aos direitos da psicologia. In: Revista Infância e Juventude, n.3, p.61-70, jul./set.1999.

MACHADO, Marina Marcondes. A poética do brincar. São Paulo: Loyola, 1998.

MACHADO, Martha de Toledo. A proteção constitucional de Crianças e Adolescentes e os Direitos Humanos. Barueri, SP: Manole, 2003.

MOYLES, Janet R. Introdução. In: MOYLES, Janet R. A excelência do brincar. Porto Alegre: Artmed, 2006.

ONU. Convenção Internacional dos Direitos da Criança de 1989. Adotada em Assembléia Geral das Nações Unidas em 20 de novembro de 1989. Disponível em:

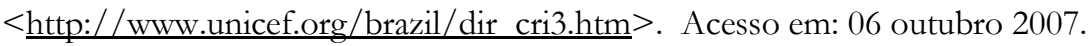


Declaração sobre os Direitos da Criança de Genebra. Aprovada em 26 de Setembro de 1924 pela Sociedade das Nações.

Declaração dos Direitos da Criança de 1959. Adotada pela Assembléia das Nações Unidas de 20 de novembro de 1959 e ratificada pelo Brasil. Disponível em: $<$ http://www.unicef.org/brazil/decl_dir.htm>. Acesso em: 6 out. 2016.

ONU. Declaração dos Direitos da Criança de 1959. Adotada pela Assembléia das Nações $<$ http://www.unicef.org/brazil/decl dir.htm>. Acesso em: 06 outubro 2007

POSTMAN, Neil. O desaparecimento da infância. Rio de Janeiro: Graphia, 2002. 190p.

SACRISTÁN, José Gimeno. O aluno como invenção. Porto Alegre: Artmed, 2005.

SANTOS, Marco Antonio Cabral dos. Criança e criminalidade no início do século. In: PRIORE, Mary Del (org). História das Crianças no Brasil. 2 ed. São Paulo:Contexto, 2000. p.210-30.

SOARES. Natália Fernandes. Direitos da criança: utopia ou realidade. In: Revista Infância e Juventude, Lisboa, n.4, out./dez. 1997. p. 101-26.

VERCELONE, Paolo. Comentário ao art. 3 do ECA. In: CURY, Munir (coord). Estatuto da Criança e do Adolescente comentado: comentários jurídicos e sociais. 3 ed. São Paulo: Malheiros Editores, 2000, p. 17-20.

WAJSKOP, Gisela. Brincar na pré-escola. 6 ed. São Paulo: Cortez, 2005. Coleção Questões da Nossa Época, v. 48. 119p.

ZUCHETTI, Dinora Tereza; MOURA, Eliana Perez Gonçalves de. Educação integral. Uma questão de direitos humanos? In: Revista Ensaio: avaliação, políticas Educacionais. Rio de Janeiro, v.25, n. 94, p. 257276, jan./mar. 2017. 